\title{
Venous Cord Blood
}

National Cancer Institute

\section{Source}

National Cancer Institute. Venous Cord Blood. NCI Thesaurus. Code C120840.

Blood present in the umbilical vein at the time of delivery. 